\title{
Analisis Pusat Pertumbuhan Pariwisata Di Kabupaten Lumajang
}

\section{Amanda Rakhmi Karunia}

Masuk: 24042018 / Diterima: 28062018 / Dipublikasi: 30062018

(C) 2018 Fakultas Hukum dan IImu Sosial UNDIKSHA dan IGI

\begin{abstract}
The objective of this research is to know where the tourism object is potential to be the center of tourism growth in Lumajang Regency. The location of the research was conducted on 10 tourist objects already recorded in the Tourism and Culture Department of Lumajang Regency, namely Bambang Beach, Selokambang Natural Bathing, Mandiri Giri Semeru Agung Temple, Joyokarto Baths, Kwt Lumajang Water Park, Ranu Klakah, Al-Kautsar Baths, , Goa Drops, and Bamboo Grove. The sampling technique is carried out by accidental sampling. Data analysis techniques used description analysis to explain the classification of tourism potential in Lumajang Regency. Map of Tourism Potential of Lumajang Regency is drawn using Arch GIS 10.5 program. From the results of the research, it is concluded that Selokambang Natural Bathing is a potential tourism object as the center of tourism growth in Lumajang Regency with a potential score of 102, which is the highest score compared to 10 other tourist objects.
\end{abstract}

Key words: Tourism Growth Center; Tourist Attraction

\begin{abstract}
Abstrak Tujuan yang ingin dicapai dalam penelitian ini adalah untuk mengetahui dimana objek wisata yang berpotensi dijadikan sebagai pusat pertumbuhan pariwisata di Kabupaten Lumajang. Lokasi penelitian dilakukan pada 10 objek wisata yang sudah tercatat dalam Dinas Pariwisata dan Kebudayaan Kabupten Lumajang, yaitu Pantai Bambang, Pemandian Alam Selokambang, Pura Mandara Giri Semeru Agung, Pemandian Joyokarto, Water Park KWT Lumajang, Ranu Klakah, Pemandian Al-Kautsar, Piket Nol, Goa Tetes, dan Hutan Bambu. Teknik pengambilan sampel dilakukan secara accidental sampling. Teknik analisis data menggunakan analisis deskripsi untuk menjelaskan klasifikasi potensi objek wisata di Kabupaten Lumajang. Peta Potensi Wisata Kabupaten Lumajang digambar dengan menggunakan program Arch GIS 10.5. Dari hasil penelitian diperoleh hasil bahwa Pemandian Alam Selokambang adalah objek wisata yang berpotensi sebagai pusat pertumbuhan pariwisata di Kabupaten Lumajang dengan skor potensi sebesar 102, dimana skor ini merupakan skor tertinggi dibandingkan dengan 10 objek wisata lain yang dijadikan penelitian.
\end{abstract}

Kata kunci : Pusat Pertumbuhan Pariwisata; Objek Wisata

\section{Pendahuluan}

Kabupaten Lumajang merupakan salah satu kabupaten yang terletak di Propinsi Jawa Timur. Kabupaten Lumajang terletak pada posisi $7^{\circ} 52^{\prime}-8^{\circ}$ 23' Lintang Selatan dan $112^{\circ} 50^{\prime}-113^{\circ}$ 22' Bujur Timur dengan Luas wilayah $1.790,90 \mathrm{Km}^{2}$ atau $3,74 \%$ dari luas Propinsi Jawa Timur.

Amanda Rakhmi Karunia SMA NEGERI 3 LUMAJANG Lumajang amanda.rakhmi@yahoo.com
Kabupaten Lumajang terdiri dari dataran yang subur karena diapit oleh tiga gunung berapi yaitu Gunung Semeru (3.676 mdpl), Gunung Bromo (2.329 mdpl), serta Gunung Lemongan (1.668 mdpl). Kabupaten Lumajang terletak di kawasan tapal kuda Provinsi Jawa Timur. Di bagian barat laut, yakni di perbatasan dengan Kabupaten Malang dan Kabupaten Probolinggo terdapat rangkaian Pegunungan Bromo-TenggerSemeru, dengan puncaknya Gunung Bromo yang berdekatan dengan Gunung 
Semeru. Gunung Semeru adalah gunung tertinggi di Pulau Jawa.

Dilihat dari sisi produk wisata, Kabupaten Lumajang mempunyai potensi yang baik diantaranya terdiri dari : (1) Potensi alam yang berupa hasil bumi yang melimpah seperti apukat yang tumbuh subur di daerah Ranuyoso, nangka di daerah Klakah, buah genitu (bahasa jawa : manecu) di daerah Randuagung, serta buah kelengkeng yang ditanam di sebagian besar rumahrumah penduduk di Desa Klopo Sawit, Kecamatan Candipuro (Disbudpar Kabupaten Lumajang, 2017). Daerah Pronojiwo merupakan daerah penghasil salak pondoh (salak pronojiwo) terbesar di Lumajang yang merupakan salah satu komoditas unggulan Kabupaten Lumajang. Daerah Senduro dan Pasrujambe juga merupakan daerah penghasil pisang terbesar di Kabupaten Lumajang dengan komoditas unggulan berupa pisang agung yang dijadikan sebagai icon Kabupaten Lumajang. (2) Potensi atraksi budaya masyarakat yang berupa kesenian-kesenian khas rakyat Lumajang (seperti tarian jaran kecak dan tarian Kanya Puspita yang merupakan buah karya warga Hindu di Senduro), upacara adat, legenda atau cerita rakyat yang dapat ditampilkan untuk memperkaya pengalaman wisatawan yang datang ke objek-objek wisata di Kabupaten Lumajang.

Kabupaten Lumajang memiliki sejumlah objek wisata yang relatif lengkap, mulai dari objek wisata alam (wisata tirta, hutan wisata, serta panorama alam), objek wisata buatan (taman rekreasi, gelanggang renang, kolam pancing), objek wisata minat khusus (terdapat berbagai jalur-jalur pendakian), objek wisata budaya (terdiri dari peninggalan purbakala seperti: candi, makam, dan situs), serta objek wisata religi (Pura Hindu). Akan tetapi popularitas objek wisata Kabupaten Lumajang hanya berkembang dalam skala lokal saja tidak seperti kabuapatenkabupaten tetangga di sekitarnya.

Gunung Bromo merupakan salah satu gunung api aktif yang menjadi salah satu andalan objek wisata di Provinsi Jawa Timur (Disbudpar Kabupaten Malang, 2017b). Gunung Bromo berada dalam empat wilayah kabupaten yaitu, Kabupaten Lumajang, Kabupaten Probolinggo, Kabupaten Malang, dan Kabupaten Pasuruan. Kabupaten Malang dan Kabupaten Probolinggo telah memanfaatkan dengan baik pamor Gunung Bromo untuk ikut mengembangkan potensi wisata di daerahnya sehingga pamor wisata daerah tersebut dapat naik menjadi skala yang lebih tinggi, yaitu dari skala lokal menjadi skala nasional atau skala internasional. Bahkan Kabupaten Malang saat ini sudah menjadi salah satu Kota Wisata yang banyak diminati wisatawan lokal dan mancanegara. Objek wisata yang terdapat di Kabupaten Probolinggo pun sudah mulai banyak dikenal wisatawan domestik maupun wisatawan asing (Disbudpar Kabupaten Probolinggo, 2017). Sedangkan di Kabupaten Lumajang, skala pamor objek-objek wisatanya hanya sebatas skala lokal saja. Padahal daya tarik wisata dan keanekaragaman atraksi wisatanya tidak kalah dengan Kabupaten Malang dan Kabupaten Probolinggo. Hal terebut dalam dilihat dari jumlah kunjungan wisatwan di tiga Kabupaten tersebut pada Tabel 1. 
Tabel 1. Jumlah Kunjungan Wisatawan yang Datang ke Kabupaten Malang, Kabupaten Probolinggo, dan Kabuapten Lumajang Tahun 2014-2016

\begin{tabular}{|c|c|c|c|c|}
\hline \multicolumn{2}{|c|}{ Nama Kabupaten } & 2014 & 2015 & 2016 \\
\hline \multirow[t]{2}{*}{ Kabupaten Malang } & Wisman & 80.792 & 99.873 & 129.663 \\
\hline & Wisnus & 3.170 .575 & 3.554 .609 & 5.719 .881 \\
\hline \multirow[t]{2}{*}{ Kabupaten Probolinggo } & Wisman & 21.265 & 15.702 & 8.674 \\
\hline & Wisnus & 2.881 .137 & 2.228 .724 & 1.141 .250 \\
\hline \multirow[t]{2}{*}{ Kabupaten Lumajang } & Wisman & 848 & 2.628 & 1.466 \\
\hline & Wisnus & 1.148 .996 & 1.141 .327 & 852.245 \\
\hline
\end{tabular}

Sumber : Dinas Kebudayaan dan Pariwisata Kabupaten Malang, Kabupaten Probolinggo, dan Kabupaten Lumajang, 2017

Kabupaten Lumajang perlu mengembangkan satu objek wisata yang memiliki potensi paling besar untuk dijadikan pusat kegiatan pariwisata atau pusat pertumbuhan pariwisata sehingga dapat dijadikan daerah tujuan wisata yang menarik wisatawan dan membantu perkembangan objek-objek wisata lain yang ada di sekitarnya. Dari potensi yang ada akan dapat dilakukan langkah-langkah pengembangan selanjutnya dengan tepat dan benar.

Berdasarkan latar belakang di atas peneliti berusaha untuk menganalisis dan mencari dimana lokasi objek wisata yang paling berpotensi untuk dijadikan sebagai pusat pertumbuhan pariwisata di Kabupaten Lumajang dan memetakan pusat pertumbuhan pariwisata di Kabupaten Lumajang.

Manfaat penelitian ini dapat dibagi menjadi manfaat teoritis dan manfaat praktis. Manfaat teoritis dari penelitian ini adalah untuk menerapkan teori kutub pertumbuhan dan model gravitasi yang digunakan untuk menentukan potensi lokasi wisata yang berpotensi untuk dijadikan sebagai pusat pertumbuhan pariwisata di Kabupaten Lumajang dan dengan adanya penelitian ini dapat menambah wawasan ilmu pengetahuan khususnya dalam bidang geogrfai pariwisata. Adapun manfaat praktis dalam penelitian ini adalah hasil penelitian ini dapat memberikan masukan bagi pemerintah Kabupaten Lumajang maupun instansi terkait yang berkepentingan untuk menunjang kemajuan pariwisata, khususnya pariwisata yang terdapat di Kabupaten Lumajang.

\section{Metode}

Jenis penelitian ini termasuk penelitian survai. Menurut Singarimbun \& Effendi (1989) dalam bukunya Metode Penelitian Survai menyatakan bahwa "Penelitian survai adalah penelitian yang mengambil sampel dari satu populasi dan menggunakan kuesioner sebagai alat pengumpulan data yang pokok". Objek wisata yang memiliki potensi paling tinggi merupakan objek wisata yang dapat digunakan sebagai pusat pertumbuhan pariwisata di Kabupaten Lumajang. Penelitian ini menggunakan teknik wawancara dengan panduan kuesioner yang berisi 20 pertanyaan tertulis yang diberikan kepada responden untuk dijawab. Dalam teknik wawancara ini penulis menggunakan pertanyaan tertutup dengan multiple choice item (Sanafiah, 1995) yang disebarkan di 10 objek wisata yang dipilih. 
Adapun 10 objek wisata yang dijadikan penelitian adalah : Pantai Bambang, Pemandian Alam Selokambang, Pura Mandara Giri Semeru Agung Lumajang, Pemandian Joyokarto, Water Park (KWT Lumajanag), Ranu Klakah, Pemandian Al-Kautsar, Piket Nol, Goa Tetes, serta Hutan Bambu. Pemilihan 1okasi objek wisata tersebut dilakukan karena (1) Jumlah pengunjung 93ariable lebih banyak dibandingkan dengan objek wisata yang lain (2) Dijadikan sebagai icon pariwisata Kabupaten Lumajang (3) Sudah dapat mewakili objek wisata lain yang mempunyai kesamaan karakter atraksi wisata.

Teknik wawancara dengan panduan kuesioner digunakan untuk menggali informasi mengenai 93ariable daya tarik objek wisata (5 pertanyaan), variable sikap pedagang (2 pertanyaan), 93ariable kondisi objek wisata (1 pertanyaan), 93ariable tingkat kebersihan (1 pertanyaan), 93ariable kondisi keamanan (2 pertanyaan), 93ariable fasilitas penunjang kepariwisataan (7 pertanyaan), 93ariable promosi (1 pertanyaan), serta 93ariable aksesibilitas (1 pertanyaan).

Penelitian ini juga menggunakan teknik pengukuran. Pengukuran dilakukan untuk memperoleh data mengenai : (1) Variabel jarak antar kawasan lokasi objek wisata (2) Variabel jarak objek wisata terhadap permukiman (3) Variabel jarak objek wisata ke ibu kota kabupaten. Adapun alat yang digunakan dalam yaitu: Instrumen pengukuran, GPS serta Aplikasi ArcGIS 10.5.

Penentuan responden wisatawan yang berkunjung ke masing-masing objek wisata dirasakan cukup sulit dilakukan karena jumlahnya tidak diketahui sebelumnya. Untuk itu pengambilan responden dilakukan dengan cara Accidental Sampling atau pengambilan sampel secara kebetulan tanpa direncanakan terlebih dahulu (Sugiyono, 2007). Pengambilan jumlah sampel diperoleh dengan cara tertentu karena jenis objek wisata yang dijadikan penelitian tidak sama, yaitu mengambil $5 \%$ jumlah wisatawan dalam sehari.

Untuk menjawab permasalahan dalam mengetahui lokasi objek wisata yang mampu untuk dijadikan pusat pertumbuhan di Kabupaten Lumajang menggunakan teknik penilaian atau skoring dengan menjumlahkan seluruh skor 93ariable penelitian yang terdapat pada masing-masing objek wisata, sehingga diketahui skor potensi masing-masing objek wisata. Skor potensi tertinggi merupakan objek wisata yang berpotensi untuk dijadikan pusat pertumbuhan pariwisata di Kabupaten Lumajang. Sedangakan untuk mengetahui potensi wisata di suatu wilayah digunakan rumus sebagai berikut :

$$
\begin{aligned}
r_{1}=\frac{W_{1}}{\left(0,5 \cdot J_{1}\right)^{2}} & +\frac{W_{2}}{\left(J_{1-2}\right)^{2}}+\frac{W_{3}}{\left(J_{1-3}\right)^{2}}+\cdots \\
& +\frac{W_{n}}{\left(J_{1-n}\right)^{2}} \\
r_{2}=\frac{W_{1}}{\left(J_{2-1}\right)^{2}} & +\frac{W_{2}}{\left(0,5 \cdot J_{2}\right)^{2}}+\frac{W_{3}}{\left(J_{2-3}\right)^{2}}+\cdots \\
& +\frac{W_{n}}{\left(J_{2-n}\right)^{2}}
\end{aligned}
$$

(Agus dan Murtini, $2007: 82$ )

Keterangan:

$\begin{array}{ll}\mathrm{PW}_{1} & =\text { potensi wisata di lokasi } 1 \\ \mathrm{PW}_{2} & =\text { potensi wisata di lokasi } 2 \\ \mathrm{~J}_{1-2} & =\text { jarak antar lokasi } 1 \text { dan lokasi } 2 \\ \mathrm{~J}_{2-3} & =\text { jarak antar lokasi } 2 \text { dan lokasi } 3 \\ \mathrm{~J}_{1} & =\text { jarak antara lokasi } 1 \text { dengan } \\ & \text { lokasi terdekat dari lokasi } 1\end{array}$


$\mathrm{J}_{2} \quad=$ Jarak antara lokasi 2 dengan lokasi terdekat dari lokasi 2

$\mathrm{W}_{1}, . . \mathrm{W}_{\mathrm{n}}=$ hasil pengukuran skor potensi di lokasi 1, 2, 3, $n$.

Peneliti menggunakan model gravitasi untuk mengetahui potensi lokasi objek wisata dari beberapa lokasi objek wisata dalam suatu wilayah sehingga dapat digambar peta potensi wisatanya. Peta potensi wisata digambarkan dengan menghubungkan garis-garis (isopleth atau equi-potensial lines) pada tempat-tempat dengan potensi wisata yang sama yaitu dinyatakan dalam persentase terhadap tempat dengan potensi wisata tertinggi. Untuk mengetahui potensi wisata di suatu wilayah (Yoeti, 1983).

Isopleth adalah gambaran atau peta potensi wisata yang digambarkan dengan menghubungkan tempattempat yang memiliki potensi wisata yang sama yang dinyatakan dalam presentase tempat dengan potensi wisata yang tertinggi di suatu wilayah (Utama \& Mahadewi, 2018).

\section{Hasil dan Pembahasan}

Berdasarkan survai yang dilakukan peneliti terhadap 10 objek wisata di Kabupaten Lumajang, objek wisata yang dapat dijadikan pusat pertumbuhan pariwisata di Kabupaten Lumajang adalah Pemandian Alam Selokambang dengan skor potensi sebesar 102. Secara ringkas skor potensi masing-masing objek wisata disampaikan dalam Tabel 2.

Tabel 2. Skor Potensi Masing-Masing Objek Wisata

\begin{tabular}{|c|c|c|}
\hline Objek Wisata & Jenis Wisata & Skor Potens \\
\hline Pantai Bambang & Bahari & 97 \\
\hline Pemandian Alam Selokambang & Alam & 102 \\
\hline Pura Mandara Giri Semeru Agung & Religi & 98 \\
\hline Pemandian Joyokarto & Buatan & 96 \\
\hline Water Park (KWT) & Buatan & 96 \\
\hline Ranu Klakah & Alam & 83 \\
\hline Pemandian Al-Kautsar & Buatan & 82 \\
\hline Piket Nol & Panorama Alam & 82 \\
\hline Goa Tetes & Minat Khusus & 70 \\
\hline Hutan Bambu & Hutan & 80 \\
\hline
\end{tabular}

Sumber : Data primer yang diolah, 2017

Pemandian

alam

Selokambang terletak di Desa Purwosono Kecamatan Sumbersuko sekitar 7,4 Km dari arah barat Kota Lumajang. Menurut catatan Pemerintah Kabupaten Lumajang, debit sumber air Selokambang mencapai lebih dari 1.350 meter kubik per detik, sebagian dimanfaatkan perusahaan daerah air minum (PDAM) setempat untuk memenuhi kebutuhan air bersih masyarakat Kota Lumajang. Selain kolam renang induk yang luasnya mencapai $1.000 \mathrm{~m}^{2}$, di kompleks ini juga tersedia kolam renang khusus untuk anak-anak, kolam pemancingan, beraneka ragam fasilitas bermain anak-anak, serta sarana olahraga. Karena itu, lokasi ini banyak dimanfaatkan untuk rekreasi keluarga. Pengelolaan Pemandian Selokambang pada tahun 2007 - 2009 dipegang oleh 
PD Semeru dan saat ini pengelolaan dipegang oleh Dinas Kebudayaan dan Pariwisata Kabupaten Lumajang.
Secara berdasarakan hasil survai yang dilakukan peneliti di Pemandian Alam Selokambang disampaikan dalam Tabel 3.

Tabel 3. Hasil Penelitian di Objek Wisata Pemandian Alam Selokambang

\begin{tabular}{lcccc}
\hline \multicolumn{1}{c}{ Variabel Penelitian } & $\begin{array}{c}\text { Rata-Rata } \\
\text { Kuisioner }\end{array}$ & Kategori & $\begin{array}{c}\text { Hasil } \\
\text { Pengukuran }\end{array}$ & $\begin{array}{c}\text { Skor } \\
\text { Potensi }\end{array}$ \\
\hline Jumlah Wisatawan 3 tahun terakhir & - & & 618.914 & 10 \\
\hline Luas Kawasan Objek Wisata & - & & $7,49 \mathrm{Ha}$ & 7 \\
\hline Daya Tarik Objek Wisata & 3 & Menarik & - & 10 \\
\hline Jarak Antar Objek Wisata & - & & $23,34 \mathrm{Km}$ & 10 \\
\hline Jarak Objek dan Permukiman & - & & $181,148 \mathrm{~m}$ & 5 \\
\hline Jarak Objek Wisata ke Kota & - & & $7,4 \mathrm{Km}$ & 10 \\
\hline Sikap Pedagang & 2,63 & Ramah & - & 4 \\
\hline Kondisi Objek Wisata & 2,06 & Cukup Baik & - & 7 \\
\hline Tingkat Kebersihan & 2,62 & Bersih & - & 8 \\
\hline Kondisi Keamanan & 3,02 & Aman & - & 9 \\
\hline Fasilitas Penunjang Pariwisata & 2,36 & Cukup Baik & - & 5 \\
\hline Promosi & 1 & Kurang & - & 7 \\
\hline Aksesibilitas & 3,02 & Mudah & - & 10 \\
\hline & JUMLAH TOTAL & & 102 \\
\hline
\end{tabular}

Sumber : Data primer yang diolah, 2017

Berdasarkan Tabel 3 tersebut, dapat diketahui bahwa daya tarik objek wisata Pemandian Alam Selokambang tergolong dalam kategori menarik (dengan rata-rata 3 untuk variabel daya tarik objek wisata). Kabid Pemasaran Dinas Kebudayaan dan Pariwisata Kabupaten Lumajang, Agni Asmara Megatrah, S.STP menginformasikan bahwa ketika hari besar (misalnya Idul Fitri) tiba pihak pengelola Pemandian Alam Selokambang akan menjadi lebih sibuk karena objek wisata tersebut akan dibanjiri oleh wisatawan. Pemandian Alam selokambang pada hari besar tersebut biasanya mengadakan serangkaian acara berupa pentas seni berupa band musik, musik religi, orkes dangdut yang biasanya mendatangkan artis-artis top Jawa Timur, dan beragam acara lainnya. Hal tersebut yang juga menjadi salah satu daya tarik untuk mendatangi objek wisata Pemandian Alam Selokambang. Selain itu, daya tarik wisata lainnya di Pemandian Alam Selokambang adalah banyaknya atraksi wisata yang disediakan di objek wisata ini, antara seperti kolam renang dewasa (kolam renang induk yang luasnya mencapai $1.000 \mathrm{~m}^{2}$ ) dan kolam renang anak, arena bermain anak, perahu dan sepeda air, papan luncur, dan kolam pancing.

Data jumlah kunjungan wisatawan dari tahun 2014-2016 pada Tabel 4, menunjukkan bahwa Pemandian Alam Selokambang memiliki jumlah pengunjung terbesar dibandingkan objek wisata lainnya (skor potensi 10) di Kabupaten Lumajang). Informasi tersebut menunjukkan bahwa objek wisata ini merupakan objek wisata yang paling diminati wisatawan di 
Kabupaten Lumajang dikarenakan Pemandian Alam Selokambang memiliki lebih banyak atraksi wisata dibandingkan dengan objek wisata lainnya.

Tabel 4. Jumlah Kunjungan Wisatawan pada 10 Objek Wisata yang Dijadiakan Penelitian di Kabupaten Lumajang Tahun 2014-2016

\begin{tabular}{clcccccc}
\hline No. & Nama Objek Wisata & \multicolumn{3}{c}{ Tahun } & $\begin{array}{c}\text { Jumlah } \\
\text { Wisatawan }\end{array}$ & Peringkat & $\begin{array}{c}\text { Skor } \\
\text { Potensi }\end{array}$ \\
\cline { 2 - 6 } 1 & 2014 & 2015 & 2016 & & 8 \\
\hline 2 & Pantai Bambang & 103.788 & 185.458 & 142.817 & 262.979 & 3 & 8 \\
\hline 3 & Pura Mandara Giri & 42.012 & 185.458 & 142.817 & 618.914 & 1 & 10 \\
\hline 4 & Pemandian Joyokarto & 10.049 & 49.007 & 92.566 & 174.422 & 5 & 6 \\
\hline 5 & Water Park & 103.788 & 185.458 & 142.817 & 432.063 & 2 & 9 \\
\hline 6 & Ranu Klakah & 3.574 & 3.884 & 1.779 & 9.237 & 10 & 1 \\
\hline 7 & Pemandian Al- & 42.012 & 42.117 & 43.714 & 127.936 & 6 & 5 \\
& Kautsar & & & & & & \\
\hline 8 & Piket Nol & 2.401 & 5.150 & 4368 & 11.919 & 9 & 2 \\
\hline 9 & Goa Tetes & 6.834 & 8.765 & 2.949 & 18.548 & 8 & 3 \\
\hline 10 & Hutan Bambu & 9.209 & 10.843 & 1.709 & 21.756 & 7 & 4 \\
\hline
\end{tabular}

Pada variabel aksesibilitas menunjukkan bahwa aksesibilitas menuju objek wisata Pemandian Alam Selokambang lebih baik dari pada aksesibilitas menuju ke objek wisata lainnya yang dijadikan penelitian (dapat dilhat pada Tabel 5). Aksesibilitas yang mudah menuju lokasi objek wisata Pemandian Alam Selokambang yang didukung jalan beraspal dengan kondisi jalan baik dan tidak bergelombang memudahkan berbagai alat transportasi menuju lokasi objek wisata tersebut. Alat transportasi umum untuk menuju objek wisata Pemadian Alam Selokambang dapat menggunakan angkutan pedesaan (sering disebut 'kol') dan ojek (ojek online maupun ojek konvensional).

Tabel 5. Hasil Kuesioner Variabel Aksesibilitasi di Objek Wisata yang Dijadikan Penelitian

\begin{tabular}{clccc}
\hline No. & \multicolumn{1}{c}{ Nama Objek Wisata } & Rata-Rata & Peringkat & Skor Potensi \\
\hline 1 & Pantai Bambang & 3 & 2.2 & 9 \\
\hline 2 & Selokambang & 3,02 & 1 & 10 \\
\hline 3 & Pura Mandara Giri Semeru Agung & 3 & 2.2 & 9 \\
\hline 4 & Pemandian Joyokarto & 2,55 & 3 & 8 \\
\hline 5 & Water Park & 3 & 2.3 & 9 \\
\hline 6 & Ranu Klakah & 2 & 4 & 7 \\
\hline 7 & Pemandian Al-Kautsar & 3 & 2.4 & 9 \\
\hline 8 & Piket Nol & 3 & 2.5 & 9 \\
\hline 9 & Goa Tetes & 1,62 & 5 & 6 \\
\hline 10 & Hutan Bambu & 3 & 2.6 & 9 \\
\hline
\end{tabular}

Sumber : Data primer yang diolah, 2017 
Selain itu, jarak dengan pusat kota yang relatif lebih dekat yaitu $\pm 7,4$ $\mathrm{Km}$ (dapat dilihat pada Tabel 6) menjadi salah satu pertimbangan wisatawan untuk mengunjungi objek wisata Pemandian Alam Selokambang dibandingkan dengan objek wisata lain yang dijadikan penelitian.

Tabel 6. Jarak Objek Wisata yang Dijadikan Penelitian ke lbu Kota Kabupaten Lumajang (Titik Nol kabupaten Lumajang)

\begin{tabular}{rlccc}
\hline NO. & \multicolumn{1}{c}{ Nama Objek Wisata } & $\begin{array}{c}\text { Jarak ke lbu Kota } \\
\text { Kabupaten }(\mathrm{Km})\end{array}$ & Peringkat & $\begin{array}{c}\text { Skor } \\
\text { Potensi }\end{array}$ \\
\hline 1 & Pantai Bambang & 25,9 & 7 & 4 \\
\hline 2 & Selokambang & 7,4 & 1 & 10 \\
\hline 3 & Pura Mandara Giri Semeru Agung & 19,3 & 5 & 6 \\
\hline 4 & Pemandian Joyokarto & 12,3 & 3 & 8 \\
\hline 5 & Water Park & 7,9 & 2 & 9 \\
\hline 6 & Ranu Klakah & 20 & 6 & 5 \\
\hline 7 & Pemandian Al-Kautsar & 14,5 & 4 & 7 \\
\hline 8 & Piket Nol & 39,2 & 9 & 2 \\
\hline 9 & Goa Tetes & 55,6 & 10 & 1 \\
\hline 10 & Hutan Bambu & 29,9 & 8 & 3 \\
\hline
\end{tabular}

Sumber : Data primer yang diolah, 2017

Selanjutnya, untuk membuat peta potensi wisata menggunakan model gravitasi dan potensi lokasi dengan menghubungkan garis-garis (isopleth atau equi-potensial lines) pada tempat-tempat yang memiliki potensi wisata yang sama yaitu dinyatakan dalam persentase terhadap tempat dengan potensi wisata tertinggi. Persentase potensi wisata masing-masing objek wisata di Kabupaten Lumajang disajikan dalam Tabel 6 dan peta potensi wisata Kabupaten Lumajang disajikan dalam Gambar 1.

Tabel 6. Persentase Potensi Wisata Objek Wisata di Kabupaten Lumajang

\begin{tabular}{lcccc}
\hline \multicolumn{1}{c}{ Nama Objek Wisata } & Skor & Jarak Terdekat & Nilai Potensi & Persen (\%) \\
\hline Pantai Bambang & 97 & $20,3 \mathrm{Km}$ & 1,8549 & $15,828 \%$ \\
\hline Selokambang & 102 & $7,1 \mathrm{Km}$ & 11,7187 & $100 \%$ \\
\hline Pura Mandara Giri Semeru Agung & 98 & $12,5 \mathrm{Km}$ & 3,9561 & 33,758 \\
\hline Pemandian Joyokarto & 96 & $7,1 \mathrm{Km}$ & 10,7806 & $91,994 \%$ \\
\hline Water Park & 96 & $12,5 \mathrm{Km}$ & 4,3846 & $37,415 \%$ \\
\hline Ranu Klakah & 83 & $12,5 \mathrm{Km}$ & 3,2625 & $27,840 \%$ \\
\hline Pemandian Al-Kautsar & 82 & $21,1 \mathrm{Km}$ & 1,6897 & $14,418 \%$ \\
\hline Piket Nol & 82 & $16,4 \mathrm{Km}$ & 2,1058 & $17,969 \%$ \\
\hline Goa Tetes & 70 & $16,4 \mathrm{Km}$ & 1,6142 & $13,774 \%$ \\
\hline Hutan Bambu & 80 & $20,3 \mathrm{Km}$ & 1,7265 & $14,732 \%$ \\
\hline Sumber data primer yang diolah, 2017 & & & &
\end{tabular}

Sumber data primer yang diolah, 2017 

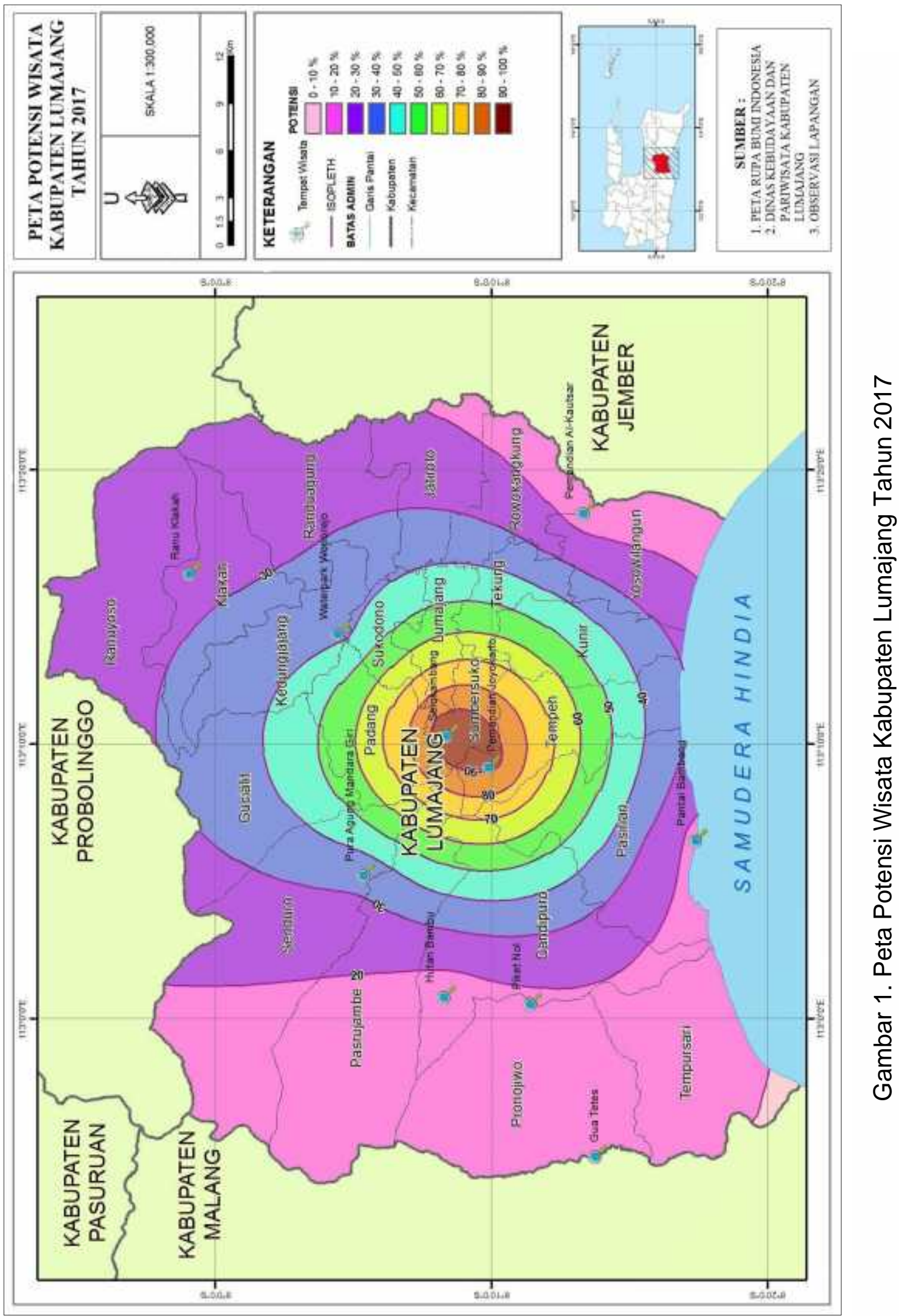


\section{Penutup}

Hasil skoring menunjukkan bahwa dari 10 objek wisata yang diteliti, Pemandian Alam Selokambang merupakan objek wisata yang ideal untuk dijadikan pusat pertumbuhan pariwisata di Kabupaten Lumajang karena memiliki skor potensi tertinggi dibandingkan dengan objek wisata lainnya yang dijadikan penelitian,yaitu 102 Hasil perhitungan persentase potensi masing-masing objek wisata yang dijadikan penelitian di Kabupaten Lumajang menunjukan bahwa Pemandian Alam Selokambang memiliki persentase potensi tertinggi untuk dijadikan pusat pertumbuhan pariwisata di Kabupaten Lumajang. Variabel penelitian yang dapat dijadikan pendukung bahwa Pemandian Alam Selokambang adalah objek wisata yang paling cocok untuk dijadikan pusat pertumbuhan pariwisata di Kabupaten Lumajang adalah : (1) Variabel daya tarik wisata, menunjukkan bahwa daya tarik wisata yang terdapat pada objek wisata Pemandian Alam Selokambang tergolong menarik. Daya tarik wisata di Pemandian Alam Selokambang didukung dengan banyaknya atraksi wisata yang disediakan, antara lain kolam renang dewasa (kolam renang induk yang luasnya mencapai $1.000 \mathrm{~m}^{2}$ ) dan kolam renang anak, arena bermain anak, perahu dan sepeda air, papan luncur,kolam pancing, dan pentas seni pada hari-hari tertentu (2) Variabel jumlah kunjungan wisatawan, menunjukkan bahwa Pemandian Alam Selokambang memiliki tingkat kunjungan wisawatan tertinggi selama tiga tahun terakhir (tahun 2014-206) dibandingkan dengan objek wisata lain yang dijadikan penelitian di Kabupaten Lumajang (3) Variabel Aksesibilitas, menunjukkan bahwa Pemandian Alam Selokambang lebih mudah dijangkau oleh wisatawan dibandingkan dengan objek wisata lain yang dijadikan penelitian (4) Variabel jarak objek wisata dengan ibu kota kabupaten, menunjukkan bahwa Pemandian Alam Selokambang memiliki jarak terdekat dengan ibu kota kabupaten dibandingkan dengan objek wisata lain yang dijadikan penelitian yaitu, 7,4 km.

Berdasarkan hasil penelitian, maka adapun sara yang diberikan adalah sebagai berikut.

1. Pengelolaan pariwisata harus melibatkan masyarakat setempat. Hal ini merupakan hal penting karena berdasarkan pengalaman pada beberapa daerah tujuan wisata, apabila tidak melibatkan masyarakat setempat berakibat pada tidak ada sumbangsih ekonomi yang diperoleh masyarakat sekitar

2. Mengajak masyarakat sekitar daerah tujuan wisata agar menyadari peran, fungsi, dan manfaat pariwisata serta merangsang mereka untuk memanfaatkan peluang-peluang yang tercipta bagi berbagai kegiatan yang dapat menguntungkan secara ekonomi.

3. Sarana dan prasarana yang dibutuhkan perlu dipersiapkan 
secara baik untuk menunjang kelancaran pariwisata, misalnya dengan pengadaan perbaikan sistem angkutan umum, jalan, telepon, internet, dan pusat pembelanjaan disekitar lokasi daerah wisata.

4. Kegiatan promosi harus beraneka ragam, selain dengan mencanangkan cara kampanye dan program I Like Lumajang seperti yang sudah dilakukan sebelumnya, kegiatan promosi juga perlu dilakukan dengan membentuk sistem informasi yang handal dengan membangun kerjasama yang baik dengan pusat informasi pada daerah-daerah lain terutama pada daerah yang berpotensi.

\section{Daftar Pustaka}

Disbudpar. (2017). Pariwisata Kabupaten Lumajang.

Disbudpar. (2017). Pariwisata Kabupaten Malang.

Disbudpar. (2017). Pariwisata Kabupaten Probolinggo.

Sanafiah, F. (1995). Format-Format Penelitian Sosial: Dasar-Dasar dan Aplikasi. Jakarta: Rajawali Pers.

Singarimbun, M., \& Effendi, S. (1989). Metodologi Penelitian Survai. Jakarta: Pustaka LP3ES.

Sugiyono. (2007). Statistika Untuk Penelitian. Bandung: Alfabeta.

Utama, I. G. B. R., \& Mahadewi, N. M. E. (2018). Metodologi Penelitian Pariwisata dan Perhotelan.

Yoeti, O. A. (1983). Pengantar Ilmu Pariwisata. Bandung: Angkasa. 